\title{
Pregnancy After Laparoscopic Sleeve Gastrectomy (LSG): The Effect of Gestational Weight Gain (GWG) On Pregnancy and Perinatal Outcomes
}

Seda SANCAK ( $\nabla$ drsedasancak@gmail.com )

University of Health Sciences https://orcid.org/0000-0003-0072-5901

Özgen ÇELER

University of Health Sciences

ELIF ÇIRAK

University of Health Sciences

ALI ÖZDEMIR

University of Health Sciences

NALAN OKUROĞLU

University of Health Sciences https://orcid.org/0000-0002-0814-2359

NURIYE ESEN BULUT

University of Health Sciences

MEHMET MAHIR FERSAHOĞLU

University of Health Sciences

AZIZ BORA KARIP

University of Health Sciences

MEHMET TIMUÇIN AYDIN

University of Health Sciences https://orcid.org/0000-0003-2835-5308

HÜSEYIN ÇiĞiLTEPE

University of Health Sciences

HASAN ALTUN

University of Health Sciences https://orcid.org/0000-0003-4978-5585

KEMAL MEMIŞOĞLU

University of Health Sciences

\section{Research Article}

Keywords: Gestational weight gain, Institute of Medicine (IOM), Laparoscopic sleeve gastrectomy, Pregnancy, Small for gestational age

Posted Date: July 15th, 2021 
DOI: https://doi.org/10.21203/rs.3.rs-607534/v1

License: (c) (1) This work is licensed under a Creative Commons Attribution 4.0 International License. Read Full License 


\section{Abstract}

Introduction: We aimed to evaluate the effect of gestational weight gain (GWG) according to Institute of Medicine (IOM) recommendation after laparoscopic sleeve gastrectomy (LSG) on maternal and fetal outcomes.

Materials and methods: A retrospective, observational study on the medical charts of pregnant women who had previously undergone LSG between 2012 and 2020. According to IOM, GWG was grouped as insufficient, appropriate, and excessive.

Results: 82 pregnancies were included in this study. GWG was appropriate in 19 of the pregnancies (23\%) and was insufficient in 18 (22\%) and excessive in 45 (55\%) of the cases. The time from operation till conception of excessive group is significantly longer than insufficient and appropriate group $\left(p_{1}: 0.000\right.$; $\left.\mathrm{p}_{2}: 0.029 ; p<0.05\right)$. There was no statistically significant difference between the groups regarding birthweight, gestational age, cesarean deliveries (CD), preterm birth, whether their child was small or large for their gestational age. There was no difference between mean hemoglobin, anemia, low ferritin level and ferritin level at early pregnancy and predelivery between groups $(p<0.05)$. There was no significant correlation between the time from operation till conception, birthweight and gestational age. There was no significant correlation between body mass index (BMI) at conception, birthweight and gestational age. There was no significant correlation between early and predelivery ferritin and hemoglobin and birthweight and gestational age. There was no correlation between mean GWG and mean BMI at conception between birthweight in either study group.

Conclusion: The gestational weight gain (GWG) did not impact maternal and neonatal outcomes.

\section{Introduction}

Obesity during pregnancy increases the frequency of obstetrical complications, including preeclampsia, gestational diabetes mellitus (GDM), miscarriage, macrosomia, cesarean delivery (CD), labor induction, and anesthetic complications. Weight loss prior to pregnancy is critical for improving maternal and fetal health outcomes [1]. When other weight-loss measures have proven unsuccessful, bariatric surgery (BS) is a treatment option for morbidly obese patients and has gained wide acceptance as a safe and effective treatment for obesity [2]. The number of bariatric procedures performed annually is rapidly increasing worldwide and laparoscopic sleeve gastrectomy (LSG) has recently emerged as the preferred surgical option [3].

Increasing studies have focused on improving maternal and fetal health outcomes after BS [4,5], but there are reports of increased risk of being small for their gestational age (SGA) $[5,6]$ and preterm birth [4-6], the cause of which is not yet clear.

Thus, maternal obesity, gestational weight gain (GWG) or gestational weight loss are all affect fetal growth [7]. Weight gain during pregnancy is an important and could affect fetal growth and correlates to 
low birthweight [7]. Insufficient GWG has been shown to be associated with lower fetal growth and birthweight and increase in SGA infants risk and in preterm birth, whereas excessive GWG was associated with higher risks of Large-for-gestational-age (LGA) and macrosomia [7]. Therefore, the Institute of Medicine (IOM) [8] standarts for adequate weight gain according to the preconception BMI to reduce the risk of growth abnormalities.

With these recommendations, it is aimed to improve maternal and child health and reduce obstetric complications. GWG has been studies in obese patients and in the general population $[9,10]$. But there is no evidence regarding weight gain recommendations in bariatric pregnancies exits [11-13]. Some relatively small studies have examined the subject of the GWG in pregnant patients after BS on maternal and neonatal outcomes; most of them included different time intervals between pregnancy and BS or a mixture of different BS techniques [14-16]. Hence the purpose of this research was to examine the effect of GWG on maternal and neonatal outcomes with a history of LSG.

\section{Materials And Methods}

A retrospective, observational study was conducted to evaluate the maternal and fetal health outcomes of 142 pregnancies in 113 women who had previously undergone LSG between 2012 and 2020 at the University of Health Sciences, Fatih Sultan Mehmet Training and Research Hospital. We analyzed the charts of women (Fig. 1). If a patient had more than one pregnancy after BS, only the first delivery was included in this study.

GWG was defined as the difference between the final weight and the weight at the conception $(\mathrm{kg})$ and was recorded for each patient as underweight, overweight, or normal, according to the recommended weight gain for their body mass index (BMI) at conception [8]. If pregnant women gained less weight than recommended, they were grouped as insufficient weight gain. If pregnant women gained more weight than recommended, they were grouped as excessive weight gain. And if the pregnant women gained appropriate weight as recommended, they were grouped as appropriate weight gain.

Prematurity was defined as a gestational age of less than 37 weeks at birth. Low birthweight was defined as a newborn weight of less than $2500 \mathrm{~g}$. Macrosomia was defined as a newborn weight of greater than $4000 \mathrm{~g}$. LGA infants were defined as those with a birthweight above the 90th percentile, and SGA as those with a birthweight below the 10th percentile. Percent excess weight loss (\%EWL) was calculated by [(presurgery weight - weight at last follow-up $(\mathrm{kg}) /$ (presurgery weight - ideal weight)] $\times 100$ with ideal weight based on body mass index (BMI) of $25 \mathrm{~kg} / \mathrm{m}^{2}$. Percent total weight loss (\%TWL) was calculated by (presurgery weight- weight at last follow-up (kg) / presurgery weight) $\times 100$.

Anemia was defined using the age-and gender-specific World Health Organization criteria (hemoglobin $(\mathrm{Hgb})<11 \mathrm{~g} / \mathrm{dl}$ during pregnancy) [17] and low ferritin was evaluated according to cutoff values $<30$ $\mathrm{ng} / \mathrm{mL}$ [18]. In addition, hemoglobin, ferritin levels at early pregnancy and at the predelivery and the administration of intravenous (iv)/oral iron supplementation were recorded. Patients had been advised to 
take multivitamins for the first postoperative year. At each follow up visit we prescribed spesific supplements if a deficiency was detected on laboratory outcomes. We treated iron deficiencies orally or if necessary intravenously.

\section{Statistical analysis}

IBM Statistics 22 program (IBM, SPSS, Turkey) was used for statistical analysis. The compliance of the parameters to normal distribution was evaluated by Kolmogorov-Smirnov and Shapiro Wilks tests. In the evaluation ot the study data, descriptive statistical methods (mean, standart deviation) as well as the Oneway Anova test for the comparison of the parameters showing normal distribution between the groups in the comparison of the quantitative data, and the Tukey HDS test was used to determine the group that caused the difference. Kruskal Wallis test was used for intergroup comparisons of parameters that did not show normal distribution, and Dunn's test was used to determine the group that caused the difference. Student $t$ test was used for the comparison of parameters showing normal distribution between two groups, and Mann Whitney $\mathrm{U}$ test was used for the comparison of parameters that did not show normal distribution between two groups. In comparison of qualitative data, Chi-Square test, Fisher's Exact Chi-Square test, Fisher Freeman Halton Test and Continuity (Yates) Correction were used. Pearson's correlation analysis was used to examine the relationships between parameters suitable for normal distribution, and Spearman'srho correlation analysis was used to examine the relationships between parameters not compatible with normal distribution. All $p$ values $<0.05$ were considered as statistically significant.

\section{Results}

GWG was appropriate according to the recommendations in only $23 \%$ of the pregnancies $(n=19)$ and was insufficient in $22 \%(n=18)$ and excessive in $55 \%(n=45)$ of the cases. We compared maternal characteristics, pregnancy, and neonatal outcomes in the three groups.

\subsection{Demographic characteristics}

Demographic characteristics are reported in Table 1. There is a statistically significant difference between the groups in mean of time from operation till conception $(p<0.05)$. The time from operation till conception of excessive group is significantly longer than insufficient and appropriate group $\left(p_{1}: 0.000\right.$; $\left.p_{2}: 0.029 ; p<0.05\right)$. There is no statistically significant difference between the insufficient and appropriate groups in mean of the time from operation till conception $(p>0.05)$.

\subsection{Pregnancy course and outcomes}

Table 2 shows pregnancy and perinatal outcomes in the groups. There is no statistically significant difference in mean BMI and weight at conception between the groups $(p>0.05)$. There was a significant difference in mean GWG between the groups $(p<0.05)$. The mean of GWG in excessive group was 
significantly higher than appropriate and insufficient group $\left(p_{1}: 0.000 ; p_{2}: 0.000 ; p<0.05\right)$, whereas there was no significant difference in mean GWG between insufficient and appropriate groups $(p<0.05)$. In the insufficient group, 3 patients lost weight during pregnancy $(-10,-14,-30 \mathrm{~kg}$ respectively).

There was no difference between mean hemoglobin, anemia, low ferritin level and ferritin level at early pregnancy and predelivery between groups $(p<0.05)$. There was no significant difference between the groups in terms of receiving iron supplement.

There was a significant difference in mode of delivery or type of labor between the groups $(p<0.05)$. Vaginal delivery in sufficient group (50\%) is significantly higher than appropriate (15.8\%) and excessive group $(24.4 \%)\left(p_{1}: 0.026 ; p_{2}: 0.049 ; p<0.05\right)$. There is no statistically significant difference in mean mode of delivery between appropriate and excessive group $(p>0.05)$. The groups were similar in terms of indications for $C D(p>0.05)$.

In our study, GDM, hypertension, preeclampsia and postpartum hemorrhage were not recorded.

\subsection{Neonatal characteristics and outcomes}

Neonatal characteristics and outcomes were reported in Table 3. There was no significant difference in the mean gestational age at delivery, birthweight, LGA and SGA births, low birthweight, and preterm delivery between the groups (Table 3 ).

There was no significant correlation between GWG, baby birth weight and gestational age. There was no significant correlation between the time from operation till conception, birthweight and gestational age. There was no significant correlation between BMI at conception, birthweight and gestational age. There was no significant correlation between early and predelivery ferritin and $\mathrm{Hbg}$ and birthweight and gestational age.

\section{Discussion}

The aim of our study was to evaluate the GWG and compare it according to the IOM recommendation [8]. In addition, the results on maternal and neonatal outcomes were evaluated by classifying GWG as insufficient, appropriate and excess according to IOM.

GWG after BS can vary widely in studies $[16,19,20]$. The average GWG was $12.59 \mathrm{~kg}$ in our study, with 3 patients losing weight during pregnancy.

Our findings are line with those of Hammeken et al. [19] showed that GWG in the RYGB group was $11.5 \pm$ $9.9 \mathrm{~kg}$ and Ceulemans et al. [16] showed that the average GWG in the malabsorptive and restrictive group was $12.5 \mathrm{~kg}$. Whereas Chagas et al. [20] found a mean GWG of $7.68 \mathrm{~kg}$ in pregnant patients who had undergone gastric bypass. 
In our study GWG was insufficient for $22 \%$, appropriate for $23 \%$ and excessive for $55 \%$ of the pregnancies. Our insufficient GWG rate was similar the general population's. The IOM [8] described a $25.5 \%$ rate of insufficient GWG in obese and normal BMI populations and 14\% rate of insufficient GWG in overweight patients. Lindberg et al. [21] showed that insufficient GWG was between $12.2 \%-25.5 \%$ in overweight and grade II obesity.

Obese patients tend to gain excessive weight gain during pregnancy. However, a higher percentage of patients in the studies presented with obesity, the pregnant women lost weight during gestation despite being overweight and obese.

This can be explained by the fact that a relatively larger proportion of the pregnant women having a surgery-to-conception interval of less than 18 months and there are in the catabolic phase and therefore cannot gain sufficient weight. As the greatest weight loss occurs during the first 6-18 months postsurgery, this period may be physiologically catabolic because of lower food intake or less absorption of nutrients. During the second year after surgery, the rate of weight loss decreases and weight stabilizes [22].

In our study, average prepregnancy BMI was $30.91 \pm 6.18 \mathrm{~kg} / \mathrm{m} 2$ and there is no statistically significant difference in mean BMI at conception between the groups. $26.9 \%$ of the patients were overweight and $53.6 \%$ were obese. The mean time from operation till conception was 27.74 months. The time from operation till conception of excessive group is significantly longer than insufficient and appropriate group. These findings are in line with those of Stentebjerg et al. [15] after RYGB. They found that $62 \%$ of the women with BS who became pregnant were still obese at conception and there was no statistically significant difference in mean BMI at conception between the groups. But $43 \%$ of their patients had insufficient GWG, which was $22 \%$ in our study. Despite being a higher percentage of patients presented with obesity in the study of Stentebjerg et al. [15] the time from operation till conception was shorter than our study. The median time from operation till conception was 14 months which was 27.74 months in our study.

Grandfils et al. [14] found that the women with BS who became pregnant were still obese at conception and women with insufficient GWG had higher pre-pregnancy BMIs when compared to women with normal or excessive GWG. There was no statistically significant difference in mean the median time from operation till conception between the groups. Grandfils et al. [14] showed that GWG was insufficient for $35 \%$, was appropriate $27 \%$ and was excessive for $38 \%$ of the pregnancies and the mean time from operation till conception of insufficient group was shorter than adapted and excessive groups.

Chagas et al. [20] showed that average prepregnancy BMI was $27.36 \pm 3.26 \mathrm{~kg} / \mathrm{m} 2.53 .3 \%$ of the patients were overweight and $23.3 \%$ were class I obese. Additionally, they showed that $51.7 \%$ of the women presenting insufficient, $34.5 \%$ of appropriate, $13.8 \%$ of excessive weight gain [20]. The mean time from operation till conception was 17.70 months. This situation can be explained by the lower BMI at conception and the shorter time from operation till conception than our results due to the fact that they gained insufficient weight. 
Finally, in a retrospective analysis of 127 pregnancies after malabsorptive and restrictive surgery,

Ceulemans et al. [16] reported that $24 \%$ of patients gained insufficient, $20 \%$ patients gained appropriate and $56 \%$ of patients gained excessive weight. These results are in line with our findings: In our study GWG was insufficient for $22 \%$, appropriate for $23 \%$ and excessive for $55 \%$ of the pregnancies. Ceulemans et al. [16] found that the women with BS who became pregnant were still obese at conception (37\% overweight, $32 \%$ obese). Although there was no difference between the groups in terms of BMI and the time from operation till conception, $56 \%$ of patients gained excessive weight $(80 \%$ of these pregnancies occured 18 months after surgery). And the LRYGB patients with BMI above $32.5 \mathrm{~kg} \mathrm{~m} 2$ gained the largest amount of weight during pregnancy [23].

In our study, there was no significant difference in the mean birthweight, LGA and SGA births, low birthweight between the groups. Considering the literature studies according to IOM, there are different results in terms of SGA risk. When et al. [24] found that SGA rate was higher in normal weight women who gained insufficient weight during pregnancy.

Catalano et al. [25] showed that an increase in the incidence of SGA was found in the obese or overweight patient group with a weight gain of less than $5 \mathrm{~kg}$ during pregnancy.

In the study that $74 \%$ of their patients had RYGB, Ceulemans et al. [16] found that a significant difference in the prevalence of SGA infants with $47 \%$ in patients with insufficient group versus $15 \%$ and $13 \%$ in those with appropriate and excessive group, respectively. Similar to findings, Grandfils et al. [14] suggest that the large proportion of women with insufficient GWG may account for increased rates of SGA after restrictive and malabsorptive surgery (34\% in the insufficient group versus $27 \%$ in the appropriate and $19 \%$ in the excessive group). Stentebjerg et al. [15] showed reductions in birth weight when GWG was insufficient, but no statistical significance was found after RYGB. Berglind et al. [26] showed that birthweight increased with GWG. Ducarme et al. [27] showed a significant reduction in low birthweight and macrosomia after BS despite lower mean GWG compared with controls with obesity.

Because one of the reasons for SGA with BS is insufficient GWG, especially among women with short interval to pregnancy after BS. The pregnant women lost weight during gestation.

In our study, there was no significant difference in the mean gestational age at delivery between the groups. These results are in line with Stentebjerg et al. [15]. Ceulemans et al. [16] showed that the gestational age at delivery was comparable between the 3 GWG groups but more patients with insufficient GWG delivered before 37 weeks. In contrast, Grandfils et al. [14] showed that gestational age was significantly different between groups and it occurred when the GWG was insufficient.

In the general population, preterm delivery has been associated with insufficient GWG, regardless of BMI at conception [9]. In our study, there was no significant difference in the mean preterm delivery between the groups. Stentebjerg et al. [15] found no difference in the prevalence of preterm deliveries between groups. Grandfils et al. [14] found patients with insufficient GWG to be at an increased risk for preterm 
labor, especially compared with those patients with excessive GWG. These results are in line with Ceulemans et al. [16].

Anemia is frequent in fertile women; and during pregnancy, Hbg and hematocrit (Hct) levels decrease physiologically due to hemodilution caused by physiological plasma volume expansion [28]. Patients who undergo both malabsorptive and restrictive procedures are at risk for iron deficiency [29].

Several studies have established a relationship between anemia and SGA and birth low birth weight [30, 31]. There was no difference between mean hemoglobin, anemia, low ferritin level and ferritin level at early pregnancy and predelivery between groups $(p<0.05)$. There was no significant difference between the groups in terms of receiving iron supplement. These results are consisting with Stentebjerg et al. [16].

There was a significant difference in mode of delivery or type of labor between the groups $(p<0.05)$. Vaginal delivery in sufficient group (50\%) is significantly higher than appropriate (15.8\%) and excessive group $(24.4 \%)$ whereas CD rate was found to be significantly lower in the groups with insufficient weight gain than the other groups, while the groups were similar in terms of indications for $C D$. The $C D$ rate in all deliveries in Turkey is high, around 53\% [32]. The frequency of cesarean section in pregnant women after BS ranges from $15.4 \%-61.5 \%$ [33]. In our study, the rate of CD was $72 \%$ and $44 \%$ of it was former CD. Grandfils et al. [15] found that, no significant difference was found between the cesarean rates between the groups that were insufficient, appropriate and excessive weight gain. Stentebjerg et al. [16] showed that, CD with excess weight gain was found to be higher than in other groups, and its detection in the excessive group was explained by the maternal age. And the lowest rate was in the group with appropriate weight gain.

\section{Conclusion}

There is no statistically significant relationship between birthweight and early pregnancy and predelivery ferritin and $\mathrm{Hb}$ level, interval from surgery to conception, CD and GWG. But GWG is probably affected by the time period between surgery and conception.

Even so, due to the lack of robust evidence, especially in long-term outcomes, practitioners should continue to recommend to delay pregnancy for 12-18 months after surgery, because of a rapid weight loss and lower food intake or less absorption of nutrients and the catabolic phase after their LSG and its specific stressful influence on the organs.

This study had some limitations, due to its retrospective nature-namely the impossibility of evaluating certain nutritional deficits, such as folic acid, magnesium and others and the fact that is it was not possible to obtain all the parameters of all the pregnant women and their newborns.

\section{Declarations}


Funding: This research did not receive any specific grant from funding agencies in the public, commercial or not-for-profit sectors.

Conflict of interest The authors declare that they have no conflicts of interest

Data Availability: The data that support this study are available upon request from the 12 corresponding author. The data are not publicly available due to privacy and ethical concerns.

Ethics approval The retrospective, observational study approved by local institutional review board and ethics committee and informed consent for this study was obtained and all the procedures being performed were part of the routine care.

\section{Each author's contribution to paper}

Seda Sancak conception and design of the work, analysis and interpretation of data, statistical analysis, overall responsibility

Özgen Çeler acquisition of data and analysis and interpretation of data

Elif Çırak acquisition of data

Nalan Okuroğlu analysis and interpretation of data,

Ali Özdemir revising it critically for important intellectual content, statistical analysis

Nuriye Esen Bulut acquisition of data

M. Mahir Fersahoğlu acquisition of data

Aziz Bora Karip analysis and interpretation of data

M. Timuçin Aydın acquisition of data

Hasan Altun critical revision of the article

Hüseyin Çiğiltepe acquisition of data

Kemal Memişoğlu acquisition of data

\section{References}

1. ACOG Committee Opinion number 315 (September 2005) Obesity in pregnancy. Obstet Gynecol. 2005; 106 (3):671-75

2. Gastrointestinal surgery for severe obesity: National Institutes of Health Consensus Development Conference Statement. Am J Clin Nutr (1992) Feb;55(2 Suppl):615S-619S. doi: 
10.1093/ajcn/55.2.615s. PMID: 1733140

3. Angrisani L, Santonicola A, lovino P et al (2017 Sep;27(9):2279-89) Bariatric Surgery and Endoluminal Procedures: IFSO Worldwide Survey 2014. Obes Surg. doi: 10.1007/s11695-017-2666-X. Erratum in: Obes Surg. 2017 Jul 5; PMID: 28405878; PMCID: PMC5562777

4. Kwong W, Tomlinson G, Feig DS (2018 Jun) Maternal and neonatal outcomes after bariatric surgery; a systematic review and meta-analysis: do the benefits outweigh the risks? Am J Obstet Gynecol 218(6):573-580

5. Galazis N, Docheva N, Simillis C, Nicolaides KH (2014 Oct) Maternal and neonatal outcomes in women undergoing bariatric surgery: a systematic review and meta-analysis. Eur J Obstet Gynecol Reprod Biol 181:45-53 doi: 10.1016/j.ejogrb.2014.07.015. Epub 2014 Jul 30. PMID: 25126981

6. Johansson K, Cnattingius S, Näslund I et al (2015) Outcomes of pregnancy after bariatric surgery. N Engl J Med. Feb 26;372(9):814 - 24. doi: 10.1056/NEJMoa1405789. PMID: 25714159

7. Goldstein RF, Abell SK, Ranasinha S et al. Association of Gestational Weight Gain With Maternal and Infant Outcomes: A Systematic Review and Meta-analysis. JAMA. 2017 Jun 6;317(21):2207-25. doi: 10.1001/jama.2017.3635. PMID: 28586887; PMCID: PMC5815056

8. Institute of Medicine (US) and National Research Council (US) Committee to Reexamine IOM Pregnancy Weight Guidelines. Weight Gain During Pregnancy: Reexamining the Guidelines. Rasmussen KM, Yaktine AL (eds) Washington (DC): National Academies Press (US); 2009. pMID: 20669500

9. Faucher M, Hastings-Tolsma M, Song J, Willoughby D, Bader SG (2016) Gestational weight gain and preterm birth in obese women: a systematic review and meta-analysis. BJOG Int J Obstet Gynaecol 123(2):199-206

10. Faucher MA, Barger MK (2015) Gestational weight gain in obese women by class of obesity and select maternal/newborn outcomes: a systematic review. Women Birth 28(3):e70-e79

11. Harreiter J, Schindler K, Bancher-Todesca D et al. Management of Pregnant Women after Bariatric Surgery. J Obes. 2018 Jun 3;2018:4587064. doi: 10.1155/2018/4587064. PMID: 29973985; PMCID: PMC6008727

12. ACOG (2009) Clinical Management Guideline, Bariatric Surgery and Pregnancy. ACOG, Washington, DC, USA

13. Press TNA (ed) (2009) IOM (Institute of Medicine) Weight Gain during Pregnancy: Reexamining the Guidelines. The National Academies Press, Washington, DC, USA

14. Grandfils S, Demondion D, Kyheng M et al (2019 Jun) Impact of gestational weight gain on perinatal outcomes after a bariatric surgery. J Gynecol Obstet Hum Reprod 48(6):401-405. doi:10.1016/j.jogoh.2019.03.001. Epub 2019 Mar 19. PMID: 30902762

15. Stentebjerg LL, Andersen LLT, Renault K, Støving RK, Jensen DM (2017 May) Pregnancy and perinatal outcomes according to surgery to conception interval and gestational weight gain in women with previous gastric bypass. J Matern Fetal Neonatal Med 30(10):1182-1188 
16. Ceulemans D, De Mulder P, Lebbe B et al. Gestational weight gain and postpartum weight retention after bariatric surgery: data from a prospective cohort study. Surg Obes Relat Dis. 2020 Dec 29:S1550-7289(20)30719-X. doi: 10.1016/j.soard.2020.12.009. Epub ahead of print. PMID: 33549505

17. World Health Organization (2011) Haemoglobin concentrations for the diagnosis of anaemia and assessment of severity. Vitamin and Mineral Nutrition Information System. http://www.who.int/vmnis/indicators/haemoglobin.pdf (accessed January 2018)

18. World Health Organization (2011) Serum ferritin concentrations for the assessment of iron status and iron deficiency in populations. Vitamin and Mineral Nutrition Information System. http://www.who.int/vmnis/indicators/ serum_ferritin.pdf (accessedJanuary 2018)

19. Hammeken LH, Betsagoo R, Jensen AN, Sørensen AN, Overgaard C (2017 Sep) Nutrient deficiency and obstetrical outcomes in pregnant women following Roux-en-Y gastric bypass: A retrospective Danish cohort study with a matched comparison group. Eur J Obstet Gynecol Reprod Biol 216:56-60 doi: 10.1016/j.ejogrb.2017.07.016. Epub 2017 Jul 12. PMID: 28732251

20. Chagas C, Saunders C, Pereira S, Silva J, Saboya C, Ramalho A (2017 Jan) Perinatal Outcomes and the Influence of Maternal Characteristics After Roux-en-Y Gastric Bypass Surgery. J Womens Health (Larchmt) 26(1):71-75 doi: 10.1089/jwh.2015.5702. Epub 2016 Dec 2. PMID: 27912030

21. Lindberg S, Anderson C, Pillai P, Tandias A, Arndt B, Hanrahan L (2016 Nov) Prevalence and Predictors of Unhealthy Weight Gain in Pregnancy. WMJ 115(5):233-237. PMID: 29095584; PMCID: PMC5313046

22. Sjöström L, Narbro K, Sjöström CD et al (2007) Swedish Obese Subjects Study. Effects of bariatric surgery on mortality in Swedish obese subjects. N Engl J Med. Aug 23;357(8):741 - 52

23. Patel JA, Patel NA, Thomas RL, Nelms JK, Colella JJ. Pregnancy outcomes after laparoscopic Rouxen-Y gastric bypass. Surg Obes Relat Dis. 2008 Jan-Feb;4(1):39-45

24. Wen T, Lv Y (2015) Inadequate gestational weight gain and adverse pregnancy outcomes among normal weight women in China. Int J Clin Exp Med 8(2):2881-2886

25. Catalano PM, Mele L, Landon MB et al Eunice Kennedy Shriver National Institute of Child Health and Human Development Maternal-Fetal Medicine Units Network. Inadequate weight gain in overweight and obese pregnant women: what is the effect on fetal growth? Am J Obstet Gynecol. 2014 Aug;211(2):137.e1-7. doi: 10.1016/j.ajog.2014.02.004. Epub 2014 Feb 11. PMID: 24530820; PMCID: PMC4117705

26. Berglind D, Willmer M, Näslund E, Tynelius P, Sørensen TI, Rasmussen F (2014 Dec) Differences in gestational weight gain between pregnancies before and after maternal bariatric surgery correlate with differences in birth weight but not with scores on the body mass index in early childhood. Pediatr Obes 9(6):427-434 doi: 10.1111/j.2047-6310.2013.00205.x. Epub 2013 Dec 11 PMID: 24339139

27. Ducarme G, Revaux A, Rodrigues A, Aissaoui F, Pharisien I, Uzan M. Obstetric outcome following laparoscopic adjustable gastric banding. Int J Gynaecol Obstet. 2007 Sep;98(3):244-7. doi: 
10.1016/j.jgo.2007.02.020. Epub 2007 Apr 16. PMID: 17433814

28. American College of Obstetricians and Gynecologists. ACOG Practice Bulletin No. 95: anemia in pregnancy. Obstet Gynecol (2008 Jul;112(1):201-7) doi: 10.1097/AOG.0b013e3181809c0d. Erratum in: Obstet Gynecol. 2020 Jan;135(1):222. PMID: 18591330

29. Enani G, Bilgic E, Lebedeva E, Delisle M, Vergis A, Hardy K (2020 Jul;34(7):3002-3010) The incidence of iron deficiency anemia post-Roux-en-Y gastric bypass and sleeve gastrectomy: a systematic review. Surg Endosc. doi: 10.1007/s00464-019-07092-3. Epub 2019 Sep 4. PMID: 31485928

30. Kaur M, Chauhan A, Manzar MD, Rajput MM (2015 Dec) Maternal Anaemia and Neonatal Outcome: A Prospective Study on Urban Pregnant Women. J Clin Diagn Res 9(12):QC04-Q8. doi:10.7860/JCDR/2015/14924.6985

31. Haider BA, Olofin I, Wang M, Spiegelman D, Ezzati M, Fawzi WW; Nutrition Impact Model Study Group (anaemia). Anaemia, prenatal iron use, and risk of adverse pregnancy outcomes: systematic review and meta-analysis. BMJ (2013) Jun 21;346: f3443. doi: 10.1136/bmj.f3443

32. Health statistics yearbook (2015) Nomenclature of territorial units for statistics and provinces. Republic of Turkey: Ministry of Health; 2015

33. Yi XY, Li QF, Zhang J, Wang ZH (2015 Jul) A meta-analysis of maternal and fetal outcomes of pregnancy after bariatric surgery. Int J Gynaecol Obstet 130(1):3-9

\section{Tables}


Table 1. Demographic characteristics of the study population

\begin{tabular}{|c|c|c|c|c|}
\hline & $\begin{array}{l}\text { Insufficient } \\
(\mathrm{n}=18)\end{array}$ & $\begin{array}{l}\text { Appropriate } \\
(\mathrm{n}=19)\end{array}$ & $\begin{array}{l}\text { Excessive ( } \mathrm{n} \\
=45)\end{array}$ & $\begin{array}{l}\mathrm{p} \\
\text { values }\end{array}$ \\
\hline $\begin{array}{l}\text { Maternal age at conception (years), } \\
\text { mean } \pm S D\end{array}$ & $31,28 \pm 5,03$ & $32,63 \pm 4,82$ & $32,40 \pm 5,19$ & ${ }^{1} 0,671$ \\
\hline Weight before LSG $(\mathrm{kg})$, mean $\pm S D$ & $\begin{array}{l}123,75 \pm \\
13,13\end{array}$ & $\begin{array}{l}121,05 \pm \\
17,81\end{array}$ & $\begin{array}{l}129,80 \pm \\
15,02\end{array}$ & ${ }^{1} 0,086$ \\
\hline Height before LSG $(m)$, mean $\pm S D$ & $1,66 \pm 0,07$ & $1,65 \pm 0,08$ & $1,65 \pm 0,05$ & ${ }^{1} 0,810$ \\
\hline BMI before $L S G\left(\mathrm{~kg} / \mathrm{m}^{2}\right)$, mean \pm SD & $44,76 \pm 3,44$ & $44,32 \pm 4,12$ & $47,56 \pm 5,96$ & ${ }^{1} 0,033^{*}$ \\
\hline $\begin{array}{l}\text { Interval from surgery to conception } \\
\text { (months) median (IQR) }\end{array}$ & $8(22,25)$ & $15(26)$ & $30(24,5)$ & ${ }^{2} 0,000 *$ \\
\hline $\begin{array}{l}\% E W L \text { from operation till conception, } \\
\text { mean } \pm S D\end{array}$ & $73,11 \pm 35,47$ & $72,71 \pm 35,88$ & $\begin{array}{l}74,80 \pm \\
20,33\end{array}$ & ${ }^{1} 0,057$ \\
\hline $\begin{array}{l}\% T W L \text { from operation till conception, } \\
\text { mean } \pm S D\end{array}$ & $31,74 \pm 15,31$ & $30,71 \pm 13,67$ & $34,45 \pm 9,11$ & ${ }^{1} 0,802$ \\
\hline Parity, median (IQR) & $1(1)$ & $0(1)$ & $0(1)$ & ${ }^{2} 0,658$ \\
\hline${ }^{1}$ Oneway ANOVA Test & \multicolumn{3}{|c|}{${ }^{2}$ Kruskal Wallis Test } & $\begin{array}{l}{ }^{*} \mathrm{p}< \\
0.05\end{array}$ \\
\hline
\end{tabular}


Table 2. Pregnancy course and outcomes

\begin{tabular}{|c|c|c|c|c|}
\hline & $\begin{array}{l}\text { Insufficient ( } \mathrm{n} \\
=18)\end{array}$ & $\begin{array}{l}\text { Appropriate }(\mathrm{n} \\
=19)\end{array}$ & $\begin{array}{l}\text { Excessive }(\mathrm{n} \\
=45)\end{array}$ & $\begin{array}{l}\mathrm{p} \\
\text { values }\end{array}$ \\
\hline $\begin{array}{l}\text { BMl at conception }\left(\mathrm{kg} / \mathrm{m}^{2}\right) \text {, mean } \\
\text { (SD) }\end{array}$ & $30,57 \pm 7,46$ & $30,80 \pm 6,91$ & $31,09 \pm 5,41$ & ${ }^{1} 0,953$ \\
\hline Weight at conception $(\mathrm{kg})$, mean (SD) & $84,11 \pm 19,95$ & $83,63 \pm 19,13$ & $84,81 \pm 13,83$ & ${ }^{1} 0,964$ \\
\hline $\begin{array}{l}\text { Weight gain during pregnancy }(\mathrm{kg}) \text {, } \\
\text { median (IQR) }\end{array}$ & $1(11)$ & $8(6,5)$ & $18(8,5)$ & ${ }^{2} 0,000 *$ \\
\hline \multicolumn{5}{|l|}{$\begin{array}{l}\text { Weight category at conception, } \mathrm{n} \\
(\%)\end{array}$} \\
\hline Underweight $(<18.5$ kg/m²) & 0 & 0 & 0 & \\
\hline Normal weight $\left(18.5-24.9 \mathrm{~kg} / \mathrm{m}^{2}\right)$ & $5(28 \%)$ & $5(26 \%)$ & $6(13 \%)$ & \\
\hline Overweight $\left(25-29.9 \mathrm{~kg} / \mathrm{m}^{2}\right)$ & $4(22 \%)$ & $3(16 \%)$ & $15(33 \%)$ & \\
\hline Obese $\left(>30 \mathrm{~kg} / \mathrm{m}^{2}\right)$ & $9(50 \%)$ & $11(58 \%)$ & $24(54 \%)$ & \\
\hline $\begin{array}{l}\text { Maternal weight at delivery }(\mathrm{kg}) \text {, } \\
\text { mean } \pm S D\end{array}$ & $84,89 \pm 14,34$ & $92,84 \pm 17,86$ & $\begin{array}{l}103,47 \pm \\
13,90\end{array}$ & ${ }^{1} 0,000 *$ \\
\hline $\begin{array}{l}\text { Maternal VKi }\left(\mathrm{kg} / \mathrm{m}^{2}\right) \text { at delivery, } \\
\text { mean } \pm S D\end{array}$ & $30,86 \pm 5,76$ & $34,16 \pm 6,29$ & $37,88 \pm 5,19$ & ${ }^{1} 0,000 *$ \\
\hline \multicolumn{5}{|l|}{ Anemia $(\mathrm{Hb}<11 \mathrm{~g} / \mathrm{dL}), \mathrm{n}(\%)$} \\
\hline early pregnancy & $1(\% 8,3)$ & $3(\% 21,4)$ & $4(\% 12,1)$ & ${ }^{3} 0,589$ \\
\hline predelivery & $2(\% 22,2)$ & $3(\% 21,4)$ & $7(\% 22,6)$ & ${ }^{3} 1,000$ \\
\hline \multicolumn{5}{|l|}{ Hemoglobin, $(g / d L)$, mean $\pm S D$} \\
\hline early pregnancy & $12,57 \pm 0,06$ & $12,21 \pm 1,39$ & $12,06 \pm 1,22$ & ${ }^{1} 0,479$ \\
\hline predelivery & $11,73 \pm 1,05$ & $12,04 \pm 1,25$ & $12,11 \pm 1,46$ & ${ }^{1} 0,766$ \\
\hline \multicolumn{5}{|l|}{ Ferritin, ng/ml, median (IQR) } \\
\hline early pregnancy & $41,4(59,3)$ & $16,2(51,4)$ & $10,2(24,2)$ & ${ }^{2} 0,118$ \\
\hline predelivery & $36,0(51,1)$ & $9,2(15,7)$ & $11,2(22,9)$ & 20,688 \\
\hline
\end{tabular}

${ }^{1}$ Oneway ANOVA Test ${ }^{2}$ Kruskal Wallis Test ${ }^{3}$ Fisher Freeman Halton Test ${ }^{4}$ Chi-Square test ${ }^{\star} \mathrm{p}<0.05$ 


\section{Table 2. Pregnancy course and outcomes}

Ferritin deficiency $(<30 \mathrm{ng} / \mathrm{ml}), \mathrm{n}$

$(\%)$

\begin{tabular}{llllr} 
early pregnancy & $4(\% 40)$ & $7(\% 53,8)$ & $21(\% 67,7)$ & ${ }^{4} 0,270$ \\
\hline predelivery & $3(\% 50)$ & $10(\% 90,9)$ & $17(\% 73,9)$ & ${ }^{3} 0,148$ \\
\hline Receiving iron supplement, $\mathrm{n}(\%)$ & $9(\% 50)$ & $15(\% 78,9)$ & $33(\% 73,3)$ & ${ }^{3} 0,330$ \\
\hline Mode of Delivery, $\mathrm{n}(\%)$ & & & \\
\hline Vaginal, $\mathrm{n}(\%)$ & $9(\% 50)$ & $3(\% 15,8)$ & $11(\% 24,4)$ & ${ }^{4} 0,050$ * \\
\hline Cesarean deliveries, $\mathrm{n}(\%)$ & $9(\% 50)$ & $16(\% 84,2)$ & $34(\% 75,6)$ & \\
\hline Indications for C/S, $\mathrm{n}(\%)$ & & & & \\
\hline Maternal request, $\mathrm{n}(\%)$ & $2(\% 22,2)$ & $3(\% 18,8)$ & $4(\% 11,8)$ & ${ }^{4} 0,586$ \\
\hline Cephalopelvic disproportion, $\mathrm{n}(\%)$ & $1(\% 11,1)$ & $2(\% 12,5)$ & $8(\% 23,5)$ & \\
\hline Low birthweight < 2500 g, n (\%) & $1(\% 11,1)$ & $2(\% 12,5)$ & $1(\% 2,9)$ & \\
\hline Repeat, $\mathrm{n}(\%)$ & $4(\% 44,4)$ & $5(\% 31,3)$ & $18(\% 52,9)$ & \\
\hline Preterm delivery, $\mathrm{n}(\%)$ & $1(\% 11,1)$ & $3(\% 18,8)$ & $1(\% 2,9)$ & \\
\hline Cord entanglement, $\mathrm{n}(\%)$ & $0(\% 0)$ & $1(\% 6,3)$ & $2(\% 5,9)$ &
\end{tabular}

${ }^{1}$ Oneway ANOVA Test ${ }^{2}$ Kruskal Wallis Test ${ }^{3}$ Fisher Freeman Halton Test ${ }^{4}$ Chi-Square test ${ }^{\star} p<0.05$ 
Table 3. Neonatal characteristics and outcomes

\begin{tabular}{|c|c|c|c|c|}
\hline & $\begin{array}{l}\text { Insufficient }(n= \\
18)\end{array}$ & $\begin{array}{l}\text { Appropriate }(n= \\
19)\end{array}$ & $\begin{array}{l}\text { Excessive }(n= \\
45)\end{array}$ & $\begin{array}{l}\mathrm{p} \\
\text { values }\end{array}$ \\
\hline \multicolumn{5}{|l|}{ Gender (F/M) } \\
\hline Male, n (\%) & $9(\% 50)$ & $10(\% 52,6)$ & $30(\% 66,7)$ & ${ }^{1} 0,367$ \\
\hline Female, n (\%) & $9(\% 50)$ & $9(\% 47,4)$ & $15(\% 33,3)$ & \\
\hline \multicolumn{5}{|l|}{ Birthweight (gram), n (\%) } \\
\hline Low birthweight < 2500 g, n (\%) & $4(\% 22,2)$ & $4(\% 21,1)$ & $7(\% 15,6)$ & 20,889 \\
\hline $\begin{array}{l}\text { Normal birthweight 2500-4000 } \\
\mathrm{g}, \mathrm{n}(\%)\end{array}$ & $14(\% 77,8)$ & $15(\% 78,9)$ & $37(\% 82,2)$ & \\
\hline High birthweight > $4000 \mathrm{~g}, \mathrm{n}(\%)$ & $0(\% 0)$ & $0(\% 0)$ & $1(\% 2,2)$ & \\
\hline SGA, n (\%) & $4(\% 22,2)$ & $4(\% 21,1)$ & $5(\% 11,1)$ & ${ }^{3} 0,482$ \\
\hline AGA, n (\%) & $14(\% 77,8)$ & $14(\% 73,7)$ & $35(\% 77,8)$ & \\
\hline LGA, n (\%) & $0(\% 0)$ & $1(\% 5,3)$ & $5(\% 11,1)$ & \\
\hline Congenital malformations, n (\%) & $0(\% 0)$ & $1(\% 5,3)$ & $0(\% 0)$ & - \\
\hline Transfer to NICU, n & 0 & 0 & 0 & - \\
\hline Preterm delivery, $\mathrm{n}(\%)$ & $2(\% 11,1)$ & $3(\% 15,8)$ & $4(\% 8,9)$ & ${ }^{2} 0,725$ \\
\hline Still birth, $\mathrm{n}$ & 0 & 0 & 0 & - \\
\hline Gestational age (weeks), mean $\pm S D$ & $38,16 \pm 1,86$ & $37,48 \pm 4,03$ & $38,23 \pm 1,99$ & ${ }^{3} 0,563$ \\
\hline \multicolumn{5}{|c|}{${ }^{1}$ Chi-Square test ${ }^{2}$ Fisher Freeman Halton Test ${ }^{3}$ Oneway ANOVA Test ${ }^{*} p<0.05$} \\
\hline
\end{tabular}

\section{Figures}




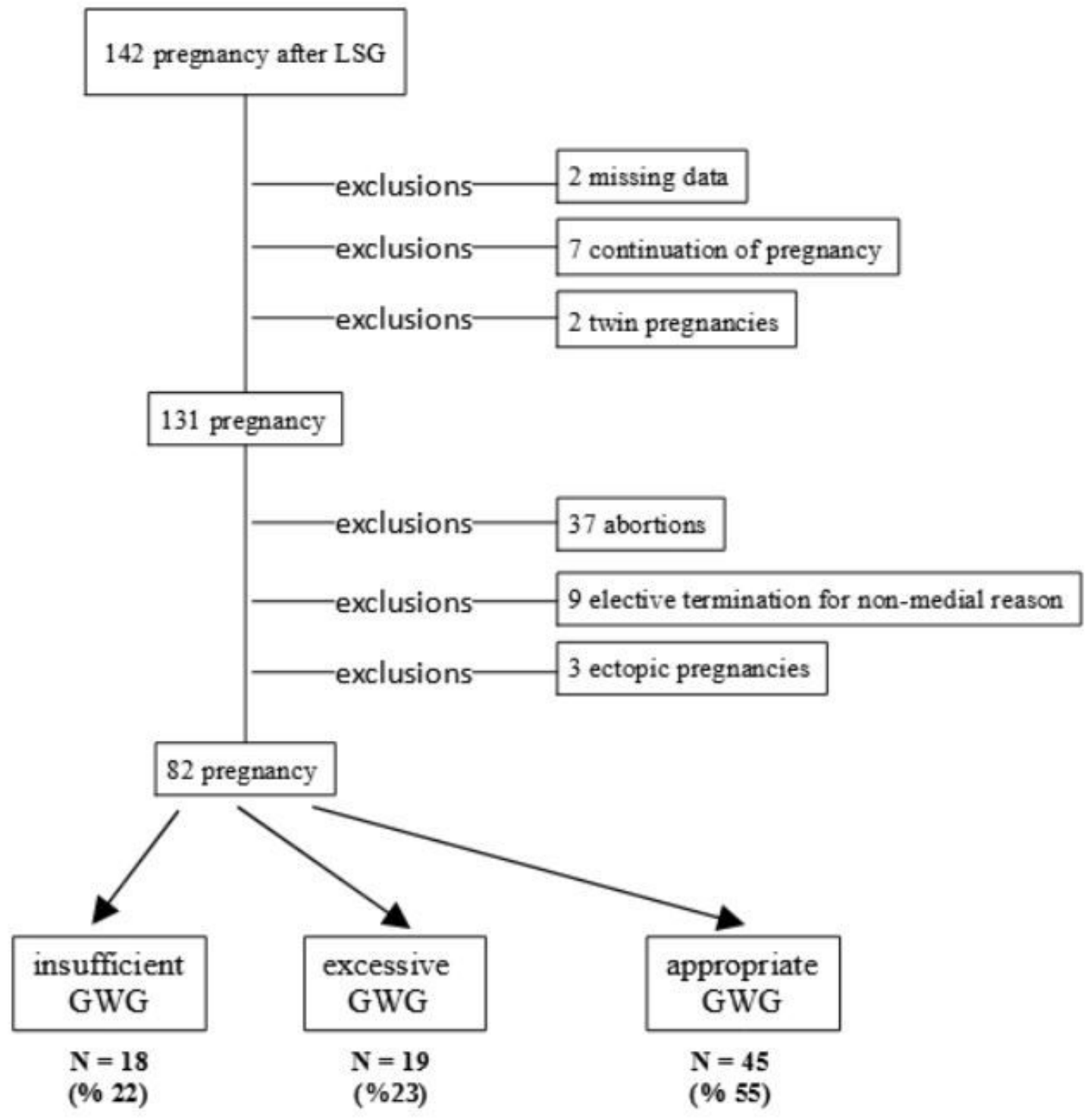

Figure 1

Flowchart of the Study 